\title{
COVID-19 in children ranging from asymptomatic to a multi-system inflammatory disease
}

\author{
A single-center study
}

Walaa Shahin, MD, Walaa Rabie, MD, Osama Alyossof, MD, Mohammed Alasiri, MD, Mohamed Alfaki, MD, MRCPCH, Elamin Mahmoud, MD, MRCPI, Muwaffak Hijazi, MD, Huda El Faraidi, MD, Hassan Alahmari, MD.

\begin{abstract}

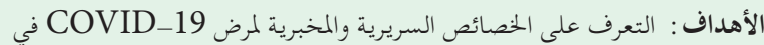

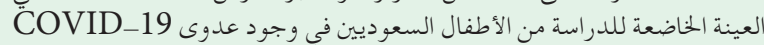
المؤكدة عن طريق اختبار ال PCR

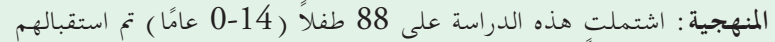

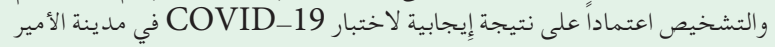

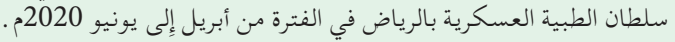

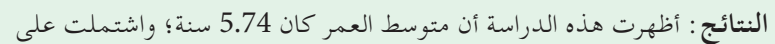
من 41

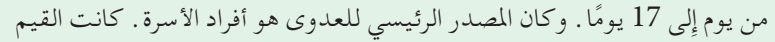

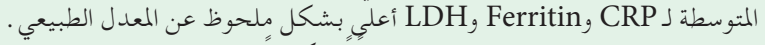

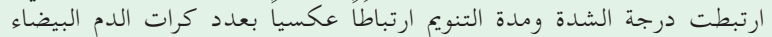

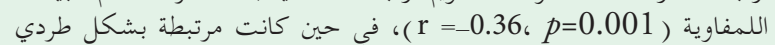

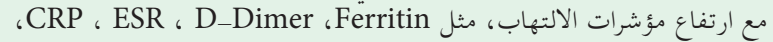

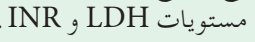

الحخلاصة: يمكن استنتاج أن تحديد الخصائص السريرية والمخبرية للأطفال

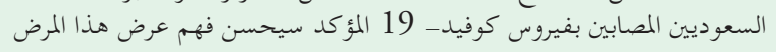

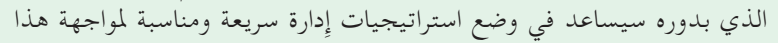

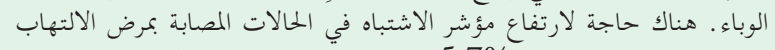

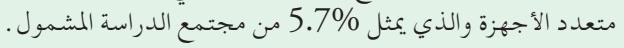

Objectives: To identify clinical and laboratory characteristics of the Saudi children with confirmed COVID-19.

Methods: Eighty-eight children (0-14 years) with COVID-19 who were admitted to Prince Sultan Military Medical City (PSMMC), Riyadh, Saudi Arabia from April to June 2020 were recruited.

Results: Mean age was $5.74 \pm 4.7$ years with $41(49.4 \%)$ males and $42(50.6 \%)$ females. The length of hospital stay (LOS) ranged from 1 to 17 days. The main source of infection was infected family members. Mean values of C-reactive protein (CRP), serum ferritin, and lactate dehydrogenase (LDH) were noticeably above normal. Degree of severity and length of stay was significantly correlated with lymphopenia $(r=-0.36 ; p=0.001)$, whereas it was positively correlated with absolute neutrophil count and with high inflammatory markers, such as CRP, LDH, and others.

Conclusions: Identifying the clinical and laboratory characteristics of the Saudi children with confirmed COVID-19 will improve understanding of this disease's presentation and will help put rapid and proper management strategies into place to face this pandemic. A high index of suspicion is needed for cases presenting with multi-system inflammatory disease, which represented $5.7 \%$ of the included study population.

Keywords: COVID-19, children, Saudi Arabia, pediatric, Multisystem inflammatory disease, MIS-c.

Saudi Med J 2021; Vol. 42 (3): 299-305 doi: 10.15537/smj.2021.42.3.20200625

From the Department of Pediatrics (Shabin), Faculty of Medicine, from the Department of Clinical and Chemical Pathology (Rabie), Kasr Alainy Faculty of Medicine, Cairo University, Cairo, Egypt; and from the Department of Pediatrics (Shahin, Alyossof, Alasiri, Alfaki, Mahmoud Hijazi, El Faraidi, Alahmari), Prince Sultan Military Medical City, Riyadh, Kingdom of Saudi Arabia.

Received 7th October 2020. Accepted 20th January 2021.

Address correspondence and reprint request to: Dr. Walaa Shahin, Department of Pediatrics, Prince Sultan Military Medical City, Riyadh, Kingdom of Saudi Arabia. E-mail: walaashahin76@gmail.com

ORCID ID: http://orcid.org/0000-0003-1040-3666

$\mathrm{O}$ December 31, 2019, a "viral pneumonia of unknown nature" was first stated in Wuhan, China, which was originally named the "2019 Novel Coronavirus" (2019-nCoV). Two months later 2020, the International Committee on Taxonomy of Viruses denoted that the new coronavirus is capable of infecting humans as Severe Acute Respiratory Syndrome Coronavirus 2 (SARS-CoV-2). Thereafter, the World Health Organization (WHO) had announced the official 
name of the illness caused by this virus as COVID-19. As of March 4, 2020, there have been 93,094 confirmed cases of COVID-19 in 77 countries, with 80,422 cases in China. ${ }^{1}$ COVID-19 is a worldwide health crisis. The clinical aspects, disease progress, and outcome in children and young adults appear to be less severe than in older individuals. Since then, COVID-19 has spread rapidly, where more than 200 countries suffered this pandemic. Until that time, pediatric patients account for $1-5 \%$ of diagnosed COVID-19 cases. $^{2}$ Mortality in children appears to be uncommon. Fever and cough are consistent features of COVID-19 in children, although infected children appear to be asymptomatic, they may play a role to transmission of infection. ${ }^{3}$ It remains unclear why children and young adults have milder disease course than older people; however, it might include changes in the immune system function in the elderly or changes either in the expression or the function of the cell receptors for SARS-CoV2 namely Angiotensin Converting Enzyme 2 (ACE2). ${ }^{3,4}$ Fever and respiratory symptoms should not be considered as the only mark of COVID-19 in children. Many other viral or bacterial infections share a common manifestation with COVID-19. Therefore, pediatricians should have a high index of suspicion to diagnose children with SARS-Cov-2 especially with asymptomatic or mild cases. Irrespective of the promising prognosis, it is significant for the children's role in the contamination cycle to be accurately determined and managed carefully. ${ }^{5}$ The disease has affected many parts of Saudi Arabia so far, with over 100,000 established cases and a reported case fatality rate of $0.73 \%{ }^{6}$ Inflammation is a crucial part of a functioning immune response. It is problematic to eradicate infections effectively without inflammation. However, SARS-CoV-2 produces severe and prolonged cytokine and chemokine responses in some patients, which are named cytokine storms, which lead to acute respiratory distress syndrome (ARDS) or multiple organ dysfunction, and eventually deterioration and death. Methods of regulating the cytokine storm include immune-modulators and cytokine inhibitors, as well as reducing the lung infiltration by inflammatory cells. Declining the mortality rate of patients with COVID-19 is achieved through proper control of the cytokine storm in its initial stage. ${ }^{7}$ Available data suggest that children may have more upper rather than

Disclosure. Authors have no conflict of interests, and the work was not supported or funded by any drug company. lower respiratory tract infection. There is also a concern about fecal to oral transmission of the virus due to evidenced shedding of the virus in the stool for many weeks after diagnosis, which points to viral replication in the gastrointestinal tract. ${ }^{7,8}$ The Centers for Disease Control (CDC) state Kawasaki Disease as an illness in a patient with fever for 5 or more days along with the presence of at least 4 of the following 5 clinical signs: rash, cervical lymphadenopathy (at least $1.5 \mathrm{~cm}$ in diameter), bilateral conjunctival injection, oral mucosal changes, and peripheral extremity changes. ${ }^{9}$

Direct detection of SARS-CoV-2 from a patient with multi-inflammatory systemic (MIS-C) disease in children might suggest its role in the disease presentation. As the COVID-19 pandemic outgrow over time, the presence of the specific SARS-CoV-2 antibody alone may be insufficient to explain the exact pathogenesis in which COVID-19 evokes an unusual immunological response leading to MIS-C. ${ }^{10,11}$

The aim of this study is to identify the clinical and laboratory characteristics of Saudi children with confirmed COVID-19, which could help to increase the awareness among pediatricians about this new virus and help establish rapid and appropriate management strategies to face this pandemic, especially in the near future, when an increased number of cases is expected in the fall.

Methods. This retrospective study recruited 88 children admitted to Prince Sultan Military Medical City (PSMMC), Riyadh, Saudi Arabia during a period of 3 months from April to June 2020. Children aged between 4 days and 14 years with a confirmed COVID-19 diagnosis were included in the study. Data were collected by the patients' primary care team and plotted in an Excel sheet. Confirmed COVID-19 cases were defined as patients with suspected COVID-19 who tested positive in a polymerase chain reaction (RT-PCR) analysis for SARS-CoV-2 through a nasopharyngeal swab in accordance with international testing guidelines, irrespective of clinical signs and symptoms. Clinical and laboratory data of the included patients were collected by carefully reviewing the patients' files.

The study was approved by the internal research board (number 1348, June 23, 2020). Each subject was given a study code number with no use of any identifiers. Data security was assured and maintained by the principal investigator. All data (both soft and hard copies) were maintained and saved within the PSMMC premises and accessed by the research team only.

Laboratory and radiological workup were guided by the Saudi Ministry of Health $(\mathrm{MOH})$ protocol and 
individualized according to the case severity. As of that time, the protocol recommended that patients who require hospital admission should be assessed properly and then daily for either thrombotic or bleeding risk. Laboratory work up include: baseline complete blood count (CBC), fibrinogen, prothrombin time (PT), activated partial thromboplastin time (aPTT), D-dimer. Baseline imaging are not recommended in case there is no clinical symptoms suggestive of venous embolism. ${ }^{5}$

Inclusion criteria were children of ages 0 to 14 years, confirmed Covid-19 by RT-PCR, and admittance to

Table 1 - Epidemiological and clinical presentation of studied population.

\begin{tabular}{|c|c|}
\hline Variable & $\begin{array}{c}\text { Frequency (\%) } \\
\qquad N=83\end{array}$ \\
\hline \multicolumn{2}{|c|}{ Contacted family member with covid-19 } \\
\hline Mother & $41(49.4)$ \\
\hline Father & $22(26.5)$ \\
\hline Both (mother \& father) & $4(4.8)$ \\
\hline Others & $16(19.3)$ \\
\hline \multicolumn{2}{|l|}{ Underlying comorbidities } \\
\hline Yes & $41(49.4)$ \\
\hline No & $42(50.6)$ \\
\hline \multicolumn{2}{|l|}{ General condition } \\
\hline Sick & $5(6.0)$ \\
\hline Well & $78(94.0)$ \\
\hline \multicolumn{2}{|l|}{ Fever } \\
\hline Yes & $53(63.9)$ \\
\hline No & $30(36.1)$ \\
\hline \multicolumn{2}{|l|}{ Sore throat } \\
\hline Yes & $17(20.5)$ \\
\hline No & $66(79.5)$ \\
\hline \multicolumn{2}{|l|}{ Cough } \\
\hline Yes & $27(32.5)$ \\
\hline No & $56(67.5)$ \\
\hline \multicolumn{2}{|l|}{ Distress } \\
\hline Yes & $9(10.8)$ \\
\hline No & $74(89.2)$ \\
\hline \multicolumn{2}{|l|}{ Hypoxia } \\
\hline Yes & $7 \quad(8.4)$ \\
\hline No & 76 (91.6) \\
\hline \multicolumn{2}{|l|}{ Diarrbea } \\
\hline Yes & $23(27.7)$ \\
\hline No & $60(72.3)$ \\
\hline \multicolumn{2}{|l|}{ Dehydration } \\
\hline Yes & $20(24.1)$ \\
\hline No & $63(75.9)$ \\
\hline \multicolumn{2}{|l|}{ Malaise } \\
\hline Yes & $29(34.9)$ \\
\hline No & $54(65.1)$ \\
\hline \multicolumn{2}{|l|}{ Chest $x$-ray findings } \\
\hline Presence of lung infiltration & $20(24.1)$ \\
\hline Normal & $59(71.1)$ \\
\hline N/A & $4(4.8)$ \\
\hline \multicolumn{2}{|l|}{ Medications } \\
\hline COVID regimen* & $9(10.8)$ \\
\hline No or nonspecific medication & $74(89.1)$ \\
\hline \multicolumn{2}{|l|}{ Recovery rate } \\
\hline Yes & $83(100)$ \\
\hline No & $0 \quad(0)$ \\
\hline
\end{tabular}

PSMMC from April to the end of June 2020. Exclusion criteria was children clinically suspected of COVID-19 infection with negative RT-PCR results.

Statistical analysis. Data were processed using Statistical Package for Social Sciences version 17 (SPSS Inc., Chicago, IL). The normality of the quantitative data distribution was examined using the D'Agostino-Pearson test. Parametric quantitative variables are presented as mean $\pm \mathrm{SD}$. Intergroup differences was compared using a student's t-test. Nonparametric numerical variables are expressed as median (interquartile range). Categorical variables are shown as numbers (percentages). Correlation studies were tested parametrically using the Pearson product moment correlation coefficient (PPMCC) or non-parametrically using the Spearman rank correlation as appropriate. Statistical significance is considered for $p$-value $<0.05$.

Results. Our study was conducted with a total of 88 children who had confirmed COVID-19 infection. The main group constituted 83 patients who presented with uncomplicated course while only 5 of the 88 children had a complicated course in the form of MIS-C. The main group's mean age was 5.74 (4.7) years, and there were $41(49.4 \%)$ males and $42(50.6 \%)$ females. The length of hospital stay (LOS) ranged from 1 to 17 days. The epidemiological and clinical characteristics of the studied population are summarized in Table 1 . The values of the main laboratory findings for the principle group are summarized in Table 2. The frequency of the children

Table 2 - Laboratory findings of the studied population (N=83).

\begin{tabular}{lc}
\hline Variables & Mean $(\mathrm{SD})$ \\
\hline White blood cell $\left(10^{\wedge 9} / \mathrm{l}\right)$ & $7.89(3.66)$ \\
$\mathrm{Hb}(\mathrm{g} / \mathrm{dl})$ & $12.06(2.38)$ \\
Platelets & $318.51(134.66)$ \\
Lymphocytes $\left(10^{\wedge 9} / \mathrm{l}\right)$ & $3.30(1.96)$ \\
Neutrophils $\left(10^{\wedge 9} / \mathrm{l}\right)$ & $3.81(3.17)$ \\
C-reactive protein $(\mathrm{mg} / \mathrm{l})$ & $49.81(24.44)$ \\
Ferritin $(\mathrm{ng} / \mathrm{ml})$ & $284.02(199.47)$ \\
Lactate dehydrogenase $(\mathrm{U} / \mathrm{L})$ & $323.96(131.34)$ \\
Partial thromboplastin time sec & $36.67(8.08)$ \\
INR & $1.057(0.11)$ \\
Vitamin D (nmol/l) & $55.84(31.55)$ \\
${ }^{*}$ D-dimer $(\mathrm{ug} / \mathrm{ml})$ & $0.4(0.30-1.37)$ \\
${ }^{*}$ Procalcitonin $(\mathrm{ng} / \mathrm{ml})$ & $0.08(0.04-0.30)$ \\
\hline \multicolumn{2}{c}{ *Data are presented as Median $\left(25^{\text {th }}-75^{\text {th }}\right.$ interquartile range $)$} \\
\hline
\end{tabular}


Table 3 - Leukocytes and inflammatory markers in studied population.

\begin{tabular}{lc}
\hline Laboratory parameter & Frequency $(\%)$ \\
\hline Leucopenia (white blood cell $\left.<410^{\wedge 9} / \mathrm{l}\right)$ & $15 / 83(18)$ \\
Lymphopenia $\left(\right.$ lymphocytes $\left.<210^{\wedge 9} / \mathrm{l}\right)$ & $18 / 83(21.7)$ \\
Neutropenia (neutrophils $\left.<1 \quad 10^{\wedge} / \mathrm{l}\right)$ & $6 / 83(7.2)$ \\
Neutrophilia (neutrophils $\left.>9.510^{\wedge} / \mathrm{l}\right)$ & $5 / 83(6)$ \\
Leukocytosis $\left(\mathrm{WBC}>2010^{\wedge 9} / \mathrm{l}\right)$ & $0 / 83$ \\
Vitamin D $<50 \mathrm{nmol} / 1$ & $25 / 42(59.5)$ \\
High Ferritin $(>124 \mathrm{ng} / \mathrm{ml})$ & $24 / 61(39.3)$ \\
D-dimer $(>0.5 \mathrm{ug} / \mathrm{ml})$ & $24 / 62(38.7)$ \\
Procalcitonin $>0.05 \mathrm{ng} / \mathrm{ml}$ & $30 / 48(62.5)$ \\
\hline
\end{tabular}

having abnormal $\mathrm{CBC}$ and inflammatory markers is illustrated in Table 3. Leukopenia and lymphopenia were encountered in approximately $20 \%$ of the study group, whereas high ferritin and high D-dimer levels were encountered in 40\%. Approximately 60\% were found to have vitamin D levels below normal levels, which was not correlated with the outcome of the disease.

The correlation studies revealed a significant negative correlation between age and vitamin D levels $(r=-0.54$, $p \leq 0.001)$. Length of hospital stay was significantly negatively correlated with lymphocyte count $(r=-0.36$,
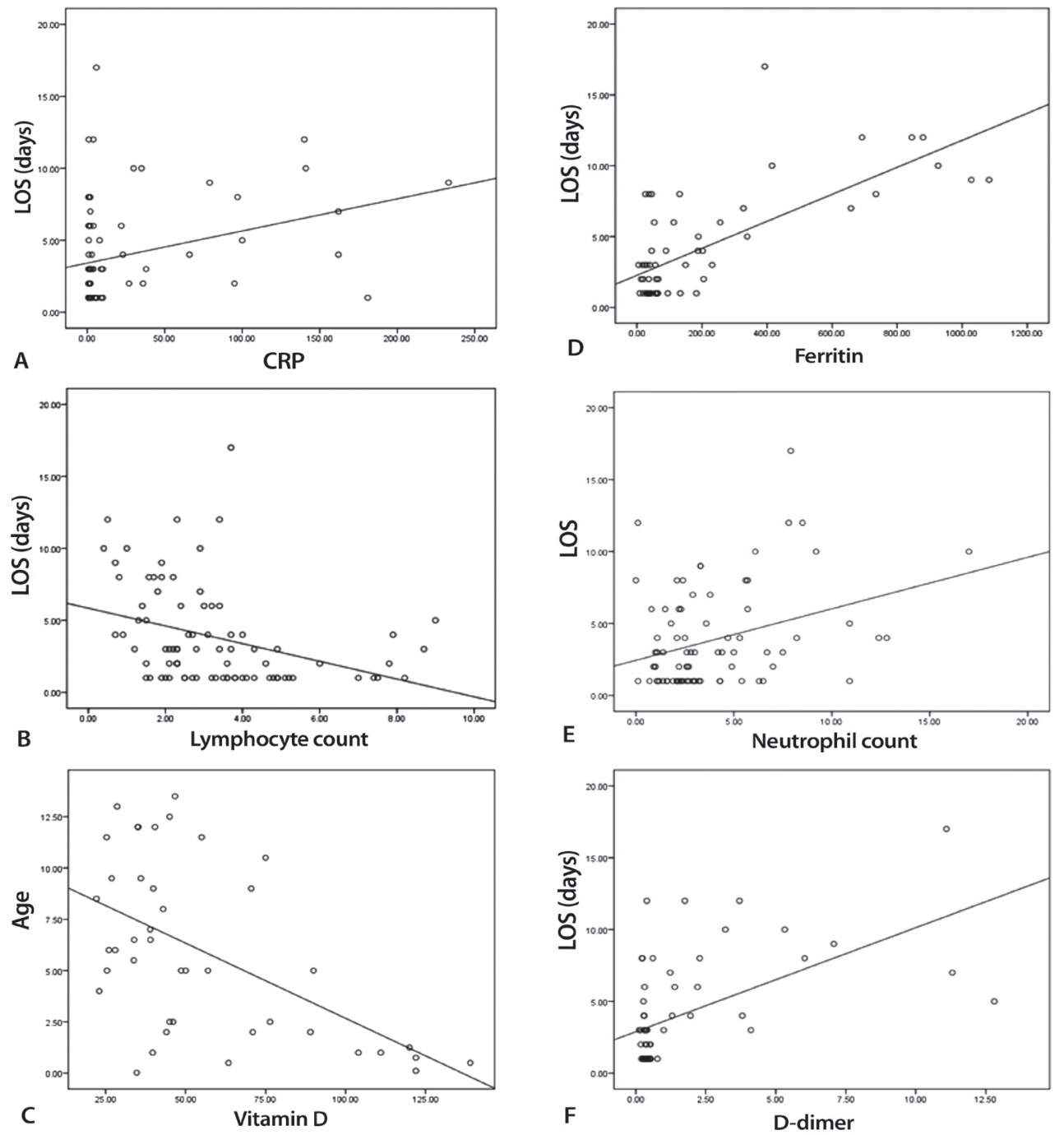

Figure 1 - Correlation between the length of stay and the different inflammatory markers as well as vitamin D level. A) CRP, B) lymphocyte count, C) vitamin D, D) ferritin, E) neutrophil count and F) D-dimer. 
$p=0.001$ ), but it was positively correlated with absolute neutrophil count and high inflammatory markers such as C-reactive protein (CRP), erythrocyte sedimentation rate (ESR), D-dimer, ferritin, lactate dehydrogenase (LDH), and INR levels $(\mathrm{r}=0.33, p=0.002, \mathrm{r}=0.31$, $p=0.007, \mathrm{r}=0.35, p=0.03, \mathrm{r}=0.57, p \leq 0.001, \mathrm{r}=0.72, p$ $\mathrm{p}=<0.001, \mathrm{r}=0.35, p=0.01, \mathrm{r}=0.30, p=0.01$, respectively; Figure 1). Vitamin D levels were significantly low in children with hypoxia $(p=0.002)$, but no significant associations were observed in cases presenting with cough $(p=0.623)$ and diarrhea $(p=0.672)$.

The data showed that our study population could be divided into 2 main groups based on the presence or absence of comorbidities. Their laboratory and clinical findings are compared in Table 4. There were 49 (59\%) recruited children who had underlying comorbidities in addition to COVID-19 infection. Increased levels of D-dimer $(p=0.023)$, the presence of cough $(p=0.005)$, and distress $(p=0.017)$ were associated with the presence of comorbidities. A non-significant difference $(p=0.236)$ was found between the presence of underlying comorbidity and other parameters, as shown in Table 4.

There were $5(5.7 \%)$ sick children with severe disease who presented with MIS-C. Their ages ranged between 8 and 12 years, there were 4 boys and 1 girl, and they all presented with fever, distress, hypoxia, malaise, dehydration, skin rash, dry lips, abdominal pain, bilateral chest $\mathrm{x}$-ray infiltrations, and variable tachycardia. They were all positive for SARS-CoV-2 IgG and IgM. Blood and urine cultures showed no growth, which ruled out the possibility of concomitant bacterial infection. Echocardiography showed normal cardiac function with no coronary dilatation. They all received a treatment protocol consisting of a combination of IVIG, pulse steroids, aspirin/antiplatelet medication, and antibiotics. They fully recovered after an average of 10 days of hospitalization.

Discussion. Early in the pandemic, there were small number of reported cases of COVID-19 in children, but as time elapsed, more cases were recognized. Little is known about this disease, which has broad-spectrum clinical presentations ranging from asymptomatic to death. However, it is reassuring that children have a relatively smooth course of the disease in comparison to adults, despite few reported deaths in otherwise healthy children. ${ }^{12}$

We hereby described the main clinical, laboratorial, and radiological characteristics of 88 children infected with SARS-CoV-2 admitted to our hospital during the period of April to June 2020. We encountered increasing numbers of cases, especially in May 2020 after the easing of curfew hours and re-opening of shopping malls. We noticed that affected family members, namely the mothers $(49.4 \%)$ and fathers $(26.5 \%)$, were the main source of infection for these children. It is clear from our study that boys (49.4\%) and girls (50.6\%) are equally infected with SARS-CoV-2.

Table 4 - Clinical and laboratory characteristics in children with and without underlying comorbidities.

\begin{tabular}{lccc}
\hline Variable & $\begin{array}{c}\text { Absence of comorbidity } \\
\mathrm{N}=34\end{array}$ & $\begin{array}{c}\text { Presence of comorbidity } \\
\mathrm{N}=49\end{array}$ & P-value \\
\hline Length of stay $(\text { days })^{*}$ & $3.48(2.1)$ & $4.26(3.4)$ & 0.312 \\
White blood cell $\left(10^{\wedge 9} /\right)^{*}$ & $7.62(3.2)$ & $8.28(4.1)$ & 0.424 \\
Lymphocytes $\left(10^{\wedge 9} / \mathrm{l}\right)^{*}$ & $3.49(1.8)$ & $3.04(2.1)$ & 0.303 \\
Neutrophils $\left(10^{\wedge 9} / \mathrm{l}\right){ }^{*}$ & $3.49(2.5)$ & $4.25(3.8)$ & 0.286 \\
C-reactive protein $\left(\mathrm{mg} / \mathrm{l}^{*}\right.$ & $48.07(31.7)$ & $49.96(18.9)$ & 0.276 \\
Procalcitonin $(\mathrm{ng} / \mathrm{ml})^{\dagger}$ & $0.08(0.03-0.22)$ & $0.14(0.05-0.3475)$ & 0.353 \\
D-dimer $(\mathrm{ug} / \mathrm{ml})^{\dagger}$ & $0.37(0.030-0.53)$ & $0.76(0.37-3.77)$ & 0.023 \\
${\text { Ferritin }(\mathrm{ng} / \mathrm{ml})^{*}}^{*}$ & $262.09(154.4)$ & $307.08(265.1)$ & 0.143 \\
Ill looking children $^{\ddagger}$ & $30(88.2)$ & $48(97.9)$ & 0.118 \\
Fever $^{\ddagger}$ & $21(61.7)$ & $32(65.3)$ & 0.679 \\
Cough $^{\ddagger}$ & $9(26.4)$ & $20(40.8)$ & 0.005 \\
Distress $^{\ddagger}$ & $2(5.8)$ & $9(18.3)$ & 0.017 \\
\hline
\end{tabular}

Values are presented as mean (SD), ${ }^{\dagger}$ Values are expressed as median $\left(25^{\text {th }}-75^{\text {th }}\right.$ interquartile range), *Values are presented as number and percentage (\%). 
The main clinical presentations were fever $(63.9 \%)$, mild cough $(32.5 \%)$, diarrhea $(27.7 \%)$, and malaise (34.9\%). Pulmonary infiltration was mild and nonspecifically detected in $24.1 \%$, whereas hypoxia was only encountered in $8.4 \%$ of children. All the included patients had favorable outcomes and smooth recovery. This agrees with what has been published before in studies from China. Dong et $\mathrm{al}^{8}$ reported in his study on 2,143 children with COVID-19 that the clinical aspects of children were relatively less severe than those of adult patients. According to published data, fever is the most common sign in children, followed by dry cough. ${ }^{8,12,13}$ Other symptoms of the different system affection such as respiratory tract, gastrointestinal tract, muscular and nervous systems, and fatigue were also reported, while some other kids were asymptomatic. , $^{81,12,13}$

Regarding moderate to severe cases, hypoxia and dyspnea could occur which required various modes of respiratory support. Acute respiratory distress syndrome (ARDS) and life-threatening multiple-organ failure has been reported in a few critical cases. ${ }^{8}$ Looking at the laboratory findings in the study population, leucopenia were present in $18 / 83(21.7 \%)$ and lymphopenia in $15 / 83(18 \%)$ cases, while neutropenia were present in only $7 \%$ and neutrophilia in $6 \%$. Inflammatory markers like CRP were increased to 4 time their normal values in $18 / 76(23.6 \%)$ cases, while proclacitonin was mildly elevated up to $2 \mathrm{ng} / \mathrm{ml}$ in $31 \%$ without concomitant bacterial infection.

Henry et $\mathrm{al}^{14}$ found similar findings when summarizing 12 studies on 66 children with reported normal leucocyte counts (69.2\%), neutropenia (6\%), neutrophilia (4.6\%), and lymphopenia (3\%). C-reactive protein were high in only $13.6 \%$ and procalcitonin in $10.6 \%$ of cases. Following the lymphocyte count and CRP is advised as a sign of the severity of infection, potential bacterial co-infection could be ruled out by checking the procalcitonin levels.

It is not well known whether SARS-CoV-19 infection adds a risk for thrombosis during critical illness in children, but statements in adults suggest a prothrombotic tendency. ${ }^{15,16}$ In our study, the average D-dimer level was $0.4(0.30-1.37) \mathrm{ug} / \mathrm{ml}$. It is used in one of the laboratories workups for risk assessment of venous thrombo-embolism (VTE) in hospitalized patients with COVID-19. Zang et al suggested that $\mathrm{D}$-dimer of $2.0 \mathrm{ug} / \mathrm{ml}$ on admission might be the proper cutoff to predict the in-hospital mortality for adults with COVID-19, since mortality rate was significantly higher in those patients with D-dimer $\geq 2.0 \mathrm{ug} / \mathrm{ml}$ than those with lower levels. ${ }^{15}$ No cutoff value for D-dimer has been determined for the severity of infection in children, so we recommend following up the dimer level and correlation with the daily clinical status of hospitalized children to detect any risk of thrombosis.

Surprisingly, 25/42 (59.5\%) of the included population was deficient in vitamin $\mathrm{D}$ with levels below $50 \mathrm{nmol} / \mathrm{L}$ according to the American Academy of Pediatrics' (AAP's) definition of vitamin D deficiency. ${ }^{17}$ Although this low level did not affect the outcome of infection, considering the well-known benefits of vitamin $\mathrm{D}$ on the health of children, they would benefit from vitamin $\mathrm{D}$ supplementation even before being infected, and vitamin $\mathrm{D}$ could have a positive effect in the course of the disease if children become infected later on. We agree with Martineau and Forouhi that vitamin D might also lower the impact of COVID-19 in populations where vitamin $\mathrm{D}$ deficiency is common and that there is no loss from giving vitamin $\mathrm{D}$ to those populations. ${ }^{18}$

This study included 41 (49.4\%) children with underlying comorbidities such as sickle cell disease, syndromic patients with global developmental delay, leukemia, Behcet disease, congenital heart disease, and prematurity. These children showed more severe illness that required hospitalization and the initiation of medications like antiviral drugs and prophylactic anti-thrombotics (low-molecular-weight heparin). This included high-risk patients for thrombosis who were ill and admitted to pediatric intensive care in addition to needing empirical antibiotics from the very beginning of admission. Increased level of D-dimer $(p=0.023)$, cough $(p=0.005)$, and distress $(p=0.017)$ were significantly associated with comorbidities. However, there was no statistically significant difference with $p>0.05$ in outcomes or other laboratory results. They all responded well and picked up in few days with complete recovery without any clinical or laboratory evidence of VTE. These are similar findings to those of DeBiasi et al, ${ }^{19}$ who compared SARS-CoV-2-infected patients who were non-critically ill and those who were critically ill and hospitalized. There were no significant differences in the presence of underlying conditions overall or any specific underlying diagnosis.

We observed that only a small proportion (5/88) of infected children were severely sick and required PICU admission, mainly due to hypoxemia and cytokine storm or MIS-C. High inflammatory markers and chest infiltration were very characteristic in addition to severe abdominal pain. All of them were previously healthy children and were infected with COVID-19 approximately 4 to 6 weeks prior to presenting with MIS-C. Initial echocardiography was normal with no coronary dilatation. All patients were under close observation in the intensive care unit. The outcomes were very promising with no mortality. 
The literature describing SARS-CoV-2 infection causing severe illness and COVID-19 in children is minimal but expanding by time. ${ }^{20}$ Multi-inflammatory systemic often occurs 1-6 weeks following infection and may overlap with the acute respiratory manifestations of acute COVID-19..$^{19,21}$ It can also complicate with coronary artery aneurysms and other extracardiac manifestations consistent with Kawasaki disease. Another reported evidence of multi-organ failure, neurologic involvement, hyperferritinemia, and cardiogenic or shock. As well as significant GI manifestations on presentation, such as vomiting, diarrhea, and severe abdominal pain. ${ }^{22}$

Study limitations. The relatively small sample size and follow up of the patients laboratories and immune status could not be achieved due to pandemic precautions.

In conclusion, COVID-19 was announced to be a global health emergency in March 2020. COVID-19 is less severe in children than adults and has a wide range of disease severity from asymptomatic to severely ill, which progresses to MIS-C. Most of the children had mild symptoms, and most of them did not require hospital admission, although they can potentially infect others. As time elapses, there will be more reports of MIS-C worldwide, which should raise the awareness of pediatricians about the serious complications of SARS-Cov2.

Early identification of cases, proper and timely management, applying preventive measures, as well as vaccine development are the keys to control the disease spread. A high index of suspicion is required for all sick children to detect Kawasaki-like or hyper inflammatory syndrome. Further large-scale studies on MIS-C are highly encouraged to identify the spectrum of the disease, different biomarkers that predict severity, and the best treatment options.

Acknowledgment. The authors would like to express their appreciation to our colleagues in the infectious diseases and infection control who were always working hard during the pandemic to protect us and to prevent the spread of infection.

\section{References}

1. Li W, Cui H, Li K, Fang Y, Li S. Chest computed tomography in children with COVID-19 respiratory infection. Pediatr Radiol 2020; 50: 796-799.

2. Ludvigsson JF. Systematic review of COVID-19 in children shows milder cases and a better prognosis than adults. Acta Paediatr 2020; 109:1088-1095.

3. Balasubramanian S, Rao NM, Goenka A, Roderick M, Ramanan AV. Coronavirus Disease 2019 (COVID-19) in Children - What We Know So Far and What We Do Not. Indian Pediatr 2020; 57: 435-442.
4. De Souza TH, Nadal JA, Nogueira RJN, Pereira RM, Brandão MB. Clinical manifestations of children with COVID-19: A systematic review. Pediatric Pulmonology 2020; 55: 18921899.

5. Saudi center for Disease Control and Prevention. Available at: https://covid19.cdc.gov.sa/. Cited Jun 10,2020

6. Ye Q, Wang B, Mao J. The pathogenesis and treatment of the 'Cytokine Storm' in COVID-19. J Infect 2020; 80: 607-613.

7. Cruz AT, Zeichner SL. COVID-19 in Children: Initial Characterization of the Pediatric Disease. Pediatrics 2020; 145 : e20200834.

8. Dong Y, MoX, Hu Y, QiX, Jiang F, Jiang Z, et al. Epidemiological characteristics of 2143 pediatric patients with 2019 coronavirus disease in China. Pediatrics 2020; 145: e20200702.

9. Centers for Disease Control and Prevention. Kawasaki Disease [Updated2018October24;Accessed2020September8]. Available from: https://www.cdc.gov/kawasaki/case-definition.html

10. Jones VG, Mills M, Suarez D, Hogan CA, Yeh D, Segal JB, et al. COVID-19 and Kawasaki Disease: Novel virus and novel case. Hosp Pediatr 2020; 10: 537-540.

11. Kim YJ, Park H, Choi YY, Kim YK, Yoon Y, Kim KR, et al. Defining Association between COVID-19 and the Multisystem inflammatory syndrome in children through the pandemic. $J$ Korean Med Sci 2020; 35: e204.

12. Mei-Jy J. Coronavirus disease 2019 in children: Current status. J Chin Med Assoc 2020; 83: 527-533.

13. Sun D, Li H, Lu XX, Xiao H, Ren J, Zhang F, et al. Clinical features of severe pediatric patients with coronavirus disease 2019 in Wuhan: a single center's observational study. World J Pediatr 2020; 16: 251-259.

14. Henry BM, Lippi G, Plebani M. Laboratory abnormalities in children with novel coronavirus disease 2019. Clin Chem Lab Med 2020; 58: 1135-1138.

15. Zhang L, Yan X, Fan Q, Liu H, Liu X, Liu Z, et al. D-dimer levels on admission to predict in hospital mortality in patients with Covid-19. J Thromb Haemost 2020; 18: 1324-1329.

16. Tang N, Li D, Wang X, Sun Z. Abnormal coagulation parameters are associated with poor prognosis in patients with novel coronavirus pneumonia. J Thromb Haemost 2020; 18 : 844-847.

17. Misra M, Pacaud D, Petryk A, Collett-Solberg PF, Kappy M. Vitamin D deficiency in children and its management: review of current knowledge and recommendations. Pediatrics 2008; 122: 398-417.

18. Martineau AR and Forouhi NG. Vitamin D for COVID-19: a case to answer? Lancet Diabetes Endocrinol 2020; 8: 735-736.

19. De Biasi RL, Song X, Delaney M, Bell M, Smith K, Pershad J, et al. Severe coronavirus disease-2019 in children and young adults in the Washington, DC, Metropolitan Region. J Pediatr 2020; 223: 199-203.e1.

20. Loi M, Branchford B, Kim J, Self C, Nuss R. COVID-19 anticoagulation recommendations in children. Pediatr Blood Cancer 2020; 67: e28485.

21. Verdoni L, Mazza A, Gervasoni A, Martelli L, Ruggeri M, Ciuffreda M, et al. An outbreak of severe Kawasaki-like disease at the Italian epicentre of the SARS-CoV-2 epidemic: an observational cohort study. Lancet 2020; 395: 1771-1778.

22. Hennon TR, Penque MD, Abdul-Aziz R, Alibrahim OS, McGreevy MB, Prout AJ, et al. COVID-19 associated Multisystem Inflammatory Syndrome in Children (MIS-C) guidelines; a Western New York approach. Prog Pediatr Cardiol. 2020; 23: 101232. 